Research Article

\title{
Study on the Predictive Algorithm of Plant Restoration under Heavy Metals
}

\author{
Jia Yu $\mathbb{D}^{1}$ and Rui Yang ${ }^{2}$ \\ ${ }^{1}$ Shenyang University, Shenyang 110044, China \\ ${ }^{2}$ Shenyang Vanke Real Estate Development Co., Ltd., Shenyang 110044, China
}

Correspondence should be addressed to Jia Yu; yujia010@cumt.edu.cn

Received 8 June 2021; Revised 8 July 2021; Accepted 29 July 2021; Published 10 August 2021

Academic Editor: Muhammad Usman

Copyright $\left({ }_{0} 2021\right.$ Jia Yu and Rui Yang. This is an open access article distributed under the Creative Commons Attribution License, which permits unrestricted use, distribution, and reproduction in any medium, provided the original work is properly cited.

Heavy metal pollution of soil is becoming a more serious issue globally. Heavy metal contamination of the soil environment is inevitable as a result of the rapid and extensive growth of industry and agriculture, resulting in unfavorable environmental circumstances for both the flora and fauna. Traditional approaches for collecting field sampling with laboratory testing of soil heavy metals are restricted not only by their time and cost but also by their inability to gather sufficient information about the spatial distribution characteristics of heavy metals in soil over a vast area. The continuous development of the urban industrial processes leads to the degree of heavy metal pollution in urban gardens. For soil monitoring and cleanup, having quick and accurate access to heavy metal concentration data is very crucial and critical. In order to improve the restoration ability of garden heavy metal pollution, a new algorithm to predict plant restoration ability under the garden heavy metal pollution environment is put forward in this study. Firstly, we analyzed the composition of garden heavy metal pollution and the harm of garden heavy metal pollution. Secondly, we identified the restoration technology of garden heavy metal pollution to plants, determine the level of garden heavy metal pollution with the help of the land accumulation index method, and reflect the average pollution water level of garden heavy metal elements with the help of Numero comprehensive pollution heatstroke. On this basis, the plant repairability prediction model was constructed with the help of wavelet function, to predict the plant repairability under garden heavy metal pollution environment and to complete the prediction of plant repairability under garden heavy metal pollution environment. The experimental results show that the proposed method was better than the traditional approaches in terms of prediction accuracy and is also less time-consuming.

\section{Introduction}

Heavy metals in soil are considered to be one of the most dangerous pollutants in the environment due to their toxicity, persistence, ease of uptake by plants, and lengthy biological lifecycle. These pollutants have the potential to disrupt the regular functioning of the soil, stress crops, and obstruct their growth. These metals can infiltrate the food chain and threaten human health if the crop absorbs them. There is no clear clue of what basically constitutes a heavy metal. Heavy metals are widely recognized as harmful compounds whose deposition in soils and uptake by vegetation have an impact on the fertility of the soil, development of the plant, and production of the plants. Lead $(\mathrm{Pb})$, cadmium $(\mathrm{Cd})$, copper $(\mathrm{Cu})$, zinc $(\mathrm{Zn})$, arsenic (As), manganese $(\mathrm{Mn})$, and chromium $(\mathrm{Cr})$ are some of the most important and accepted heavy metals. All of the mentioned heavy metals have one thing in common: they are very hazardous for both the human health and the environment. For example, $\mathrm{Pb}$ had a negative impact on the quality, productivity, and growth of the crops. Also, it is one of the main causes of blood poison in human beings. $\mathrm{Cu}$ is another important metal that is helpful for healthy plants growth but is harmful to crops development and becomes a pollutant when it is accumulated in the soil in an excessive amount. Because of its lipid solubility, Cd is one of the most phytotoxic heavy metals that are easily absorbed by plants. When the amount of this metal increases more than $0.25 \mathrm{mg}$ 
in the vegetables, it becomes a serious threat to human health and can cause various diseases [1]. Keeping in consideration the harm caused by these heavy metals, it is of great interest to check the amount of these metals in soil and monitor it closely, specifically in the agricultural areas, in order to increase the productivity of agriculture. When water and soil are contaminated with heavy metals, major health and environmental challenges are caused. Furthermore, dangerous metal concentrations in soil might cause biodiversity dysfunction by altering soil fertility and biological growth. Heavy metals cannot be dissolved or eliminated by biochemical functions; instead, they can only be changed in terms of their chemical form (known as "speciation"), which might affect their mobilization or immobility $[2,3]$.

Since the 1970s, due to the rapid development of urbanization and growing population, urban ecosystems and soils have attracted the attention of researchers. The first scholar who put forward the concept of urban soil was Bockheim, arguing that the urban soil is due to human factors and nonagricultural factors, causing the chaotic soil structure and soil pollution, and thus forming the soil with a thickness of more than $50 \mathrm{~cm}$. Due to the continuous acceleration of the urban process, the damage to the land is very serious, especially the heavy metal pollution in the process of garden construction. There is no strict unified definition of heavy metals, but, in general, it refers to metals with a density greater than $5 \mathrm{~g} / \mathrm{cm}^{3}$. The elements that constitute heavy metals such as $\mathrm{Hg}, \mathrm{Cd}, \mathrm{Pb}, \mathrm{Cr}$, and As have significant biotoxicity and have an obvious impact on human health, also called "Five-Toxic Elements" [4]. In addition, $\mathrm{Cu}, \mathrm{Zn}, \mathrm{Ni}, \mathrm{Mo}, \mathrm{Co}, \mathrm{Sn}, \mathrm{Mn}$, and other accumulation of heavy metal elements in the human body to a certain extent will also affect human health and lead to chronic poisoning. Soil heavy metal pollution mainly refers to the soil pollution caused by $\mathrm{Cu}, \mathrm{Zn}, \mathrm{Cd}, \mathrm{Pb}$, and other elements. Since 1950, foreign scholars have been concerned about the issue of heavy metal pollution in urban soils, starting from "Minamata disease" and "bone pain" caused by heavy metals $\mathrm{Hg}$ and Cd pollution in Japan. In 1970, the researchers of the United Kingdom (UK) analyzed and studied the content level of heavy metals of $\mathrm{Pb}, \mathrm{Zn}, \mathrm{Cu}$ in urban soil and found that the heavy metal contents were closely related to industry and transportation. Hence, heavy metals in urban soil were regarded as one of the indicators of urban pollution. Research on urban soil is gradually becoming a new field of research in environmental science that has a great impact on both plants and humans [5]. As the city contains a variety of sources of pollution, the heavy metal elements are released and invaded into the soil, eventually leading to a polluted urban green soil. To this end, the research on some measures to improve the ability of garden land has become the current key research problem. Researchers in this field have conducted various studies and achieved certain results [6].

Ning et al. [7] proposed the application potential of salt grass in $\mathrm{Cd}, \mathrm{Pb}$, and Li polluted salt soil restoration and studied the ability analysis of land salt improvement. His proposed method was a cost-effective method for repairing the contaminated salt soil. The analysis of $\mathrm{Cd}$ concentration, the resistance and accumulation characteristics, and the stress of three metal pollutants were studied, in order to explore the application potential of salt grass in the repair of $\mathrm{Cd}, \mathrm{Pb}$, and $\mathrm{Li}$ polluted salt soil. The results show that, with the concentration of $\mathrm{Cd}, \mathrm{Pb}$, fresh and dry weight, lowconcentration $\mathrm{Li}(\leq 20 \mathrm{mmol} / \mathrm{L})$ treatment promotes the growth of salt grass, while high-concentration $\mathrm{Li}$ ( $\geq 20 \mathrm{mmol} / \mathrm{L}$ ) treatment inhibits plant growth. The order of tolerance of $\mathrm{Cd}, \mathrm{Pb}$, and $\mathrm{Li}$ is $\mathrm{Li}>\mathrm{Pb}>\mathrm{Cd}$. $\mathrm{Cd}, \mathrm{Pb}$, and $\mathrm{Li}$ stress may reduce the absorption and transport of $\mathrm{Na}$ and $\mathrm{K}$ and affect plant growth. On the other hand, the salt grass antioxidase system shows different response mechanisms to $\mathrm{Cd}, \mathrm{Pb}$, and Li stress, and a variety of antioxidases cooperate to resist the oxidative toxicity caused by $\mathrm{Cd}, \mathrm{Pb}$, and $\mathrm{Li}$ stress. The content of salt angle roots and above ground part $\mathrm{Cd}$, $\mathrm{Pb}$, and $\mathrm{Li}$ increases with the treatment concentration, where $\mathrm{Cd}$ and $\mathrm{Pb}$ are distributed by the root and $\mathrm{Li}$ in the above ground part. The results show that the stress of $\mathrm{Cd}, \mathrm{Pb}$, and Li has strong tolerance and self-regulation, with lithium-rich properties and the potential to repair $\mathrm{Cd}, \mathrm{Pb}$, and $\mathrm{Li}$ contaminated salt soil. Planting the plant can effectively improve the ability of the salinized land, but the plant planting is affected by the natural environment and other factors and cannot be generally applicable.

Jin et al. [8] proposed a measurement method based on the repair of soil heavy metal pollution. Their proposed method uses the analysis tools brought by the Web of Science (WOS) database, HistCite citation mapping analysis software, VOSviewer visual analysis software, and Origin 9.1 mapping software. Further, they analyze the $21^{\text {st }}$ century (2000-2016) research work done in the desired domain. The article focuses on plant restoration and biore and curing/ stabilization; soil heavy metals are cadmium $(\mathrm{Cd})$, lead $(\mathrm{Pb})$, copper $(\mathrm{Cu})$, zinc $(\mathrm{Zn})$, heavy metal arsenic (As), etc. Haichao et al. [9] proposed the spatial and temporal change analysis method of regional habitat quality based on the reconstruction of land-use pattern to predict the land restoration ability. The method uses the InVEST model to reconstruct the habitat quality spatial pattern in the panYangtze River Delta region, calculates the Kappa coefficient of the simulation accuracy, and proves that the method is feasible, on the basis of this method.

Various techniques are used to study soil contamination by heavy metals. The earlier method used was field sampling followed by the chemical analysis which was expensive and ineffective. Being costly, the conventional methods were time-consuming too. The following are some of the contributions of the proposed work:

(i) This study proposes a new plant restoration ability prediction algorithm under the garden heavy metal pollution environment

(ii) Real samples are taken from the gardens soil, after the collection constitution of heavy metals elements in the soil samples was found in order to check the pollution level in it

(iii) Multiple experiments are performed to check the stability and performance of the proposed algorithm 
(iv) The experimental results show that the performance of the proposed method is way better than the other approaches in terms of prediction accuracy and forecast time overhead

The rest of the paper is organized as follow: we present a detailed discussion on the analysis of heavy metal pollution in gardens in Section 2. Section 3 illustrates prediction algorithm of phytoremediation capability in heavy metal polluted landscape environment. Section 4 demonstrates the experimental analysis, and finally we conclude our research work in Section 5.

\section{Analysis of Heavy Metal Pollution in Gardens}

In order to improve the accuracy of the plant restoration ability prediction algorithm under the garden heavy metal pollution environment, the garden heavy metal pollution environment is first analyzed and studied.

\subsection{Analysis of Environmental Pollution due to Heavy Metals} in Garden. Heavy metal refers to the combination of elements whose density level is above $5.0 \mathrm{~g} / \mathrm{cm}^{3}$ [10]. $\mathrm{Zn}$ and $\mathrm{Cu}$ are among numerous heavy metal elements that are essential for the growth of plants and animals, but an excessive amount of $\mathrm{Zn}$ elements and $\mathrm{Cu}$ elements leads to the poisoning of organisms. In the garden heavy metal pollution generally called heavy metals, mainly refers to mercury, lead, chromium, and metal arsenic that are significantly toxic to organisms; it also refers to the general heavy metal elements with a certain toxicity, such as copper, zinc, tin, cobalt, and nickel. The most noteworthy elements in heavy metals are mercury, pot, and chromium. When heavy metals are discharged with wastewater, even small concentrations may cause danger to the soil and plants. Environmental pollution caused by heavy metals is often referred to as heavy metal pollution. Other heavy metal elements such as $\mathrm{Cd}, \mathrm{Pb}$, and $\mathrm{Cr}$ are toxic to organisms even at very low concentrations, and Cd elements are the most biotoxic metals [11].

Heavy metal pollution in garden soil refers to the phenomenon of bringing heavy metals into the soil, so that the content of heavy metals in the soil is significantly higher than the background content and may cause existing or potential soil quality degradation and deterioration of ecological and environmental conditions. When the soil heavy metal pollution, air pollution, and water pollution are compared with each other, they have concealment, long-term, and irreversible characteristics, but also have the characteristics of great difficulty, high investment cost, and long treatment cycle. The high concentration of heavy metals in the garden soil will harm the growth and development of plants and then affect the output and quality of agricultural products. The harm of heavy metals to plant growth and development mainly depends on the content of heavy metals in the soil, especially the effective content of heavy metals. The main factors influencing the migration and transformation of heavy metals in the soil are the adsorption of colloids on heavy metal, the integration of various inorganic substances and organic ligands, the oxidation and reduction state of the soil, the effect of soil acidity and the ions that coexist with it, and the effect of soil microorganisms on heavy metals. Therefore, the factors affecting the migration and transformation factors and biological effect of heavy metal elements in the soil are the concentration of those elements which forms heavy metals, and it can eventually enter the human body through the "soil-plant system" and food chain, and the pollution of heavy metals affecting human health will cause more serious harm [12].

2.2. HAZOP Analysis of Heavy Metals to Measure Pollution. The following are some of the factors that are considered for the HAZOP analysis of heavy metals to measure the degree of pollution.

(a) Physical and chemical properties and biological activity of garden soil: the existence of most of the heavy metals in the garden soil is relatively stable. After entering the garden soil, it is very difficult to decompose in the process of biological material circulation and energy exchange. Hence, it is very difficult to move out of the soil. Therefore, the physical and chemical nature of the garden soil polluted by heavy metal will change, the natural ecological balance of the soil microbial system will be damaged, the type and number of microorganisms will also decline, the vitality of beneficial microorganisms will also decline, and bacteria will reproduce and spread, causing the spread of garden soil microbial diseases.

(b) Growth and development of garden plants: heavy metals pollution in the garden soil will induce the plant to produce some substances that have toxic and adverse effects on enzyme activity and physiological metabolism. For example, under the stress of some heavy metal elements, the plant will produce overoxygen, packaging, ethylene, and other substances. These substances have certain negative effects on metabolism and enzyme activity in the plant that are sometimes able to cause direct harm to it. For example, some heavy metals can bind to basic amino acids and proteins to cause the deactivation of amino acid protein, seriously resulting in plants death. Sometimes the stress of heavy metals will make plants lack a large number of nutrients (such as $\mathrm{N}, \mathrm{P}$, and K) [13] but also reduce the effectiveness of nutrients; the higher content of heavy metals in the soil will inhibit the absorption and transport of calcium, town, and other mineral elements. Heavy metal pollution will also affect the absorption of iron, leading to the decline or lack of plant iron content, causing the abnormal physiological process of iron participation and showing the symptoms of iron deficiency. 


\section{Prediction Algorithm of Phytoremediation Capability in Heavy Metal Polluted Landscape Environment}

3.1. Garden Heavy Metals Pollution in Restoration. Based on the current situation of heavy metals pollution, this paper designed a prediction algorithm of plant soil restoration. Plant restoration techniques include three major types of restoration measures: plant stabilization, plant volatilization, and plant extraction.

In recent years, the plant restoration of garden heavy metals-polluted soil mainly focuses on the following aspects:

(i) Research on the screening of heavy metals superaccumulated plants and the removal effect of those plants

(ii) Activation of plant root secretions in the soil-plant system

(iii) Migration and morphological transformation of heavy metals in the inter-root soil

(iv) Interroot microbial effect and its influence on the morphological transformation and plant absorption of heavy metals

(v) Plant resistance and detoxification mechanism of heavy metals

(vi) Mechanism of superplant absorption, transport, and accumulation of heavy metals

(vii) Restoration role of transgenic plants in heavy metal polluted soil and the breeding and screening of transgenic plants

Plant restoration has the characteristics of in situ repair, with a small disturbance to the soil environment, the governance effect is permanent, while the cost of plant repair is low. When dealing with heavy metal pollution, it can also beautify the environment, purify the air, and improve forest coverage. Posttreatment of plant restoration is relatively easy, the treatment process is basically without secondary pollution, and the recycling of heavy metals is also relatively convenient. Therefore, the treatment of heavy metal pollution soil in plant restoration gardens has a wide application prospect [14].

3.2. Design of Plaintive Plant Ability. In the garden heavy metal pollution, before the restoration of plants, the garden heavy metal pollution is first determined, and the level of the garden heavy metal pollution is determined with the help of the land accumulation index method [15] and is given as follows:

$$
P_{i}=\log _{2}\left(\frac{a_{i}}{k b_{i}}\right),
$$

where $a_{i}$ represents the actual content value of the garden heavy metal elements, $b_{i}$ illustrates the garden background value of heavy metal pollution, and $k$ demonstrates the pollution index.

The level of garden heavy metal pollution is determined according to the product index method as shown in Table 1.
TABLE 1: Grade of heavy metal pollution in gardens.

\begin{tabular}{lcc}
\hline Land accumulation index & Index level & Accumulative degree \\
\hline $5-10$ & 6 & Ponderosas \\
$4-5$ & 5 & Weight \\
$3-4$ & 4 & Serious \\
$2-3$ & 3 & Moderate weight \\
$1-2$ & 2 & Moderate \\
$0-1$ & 1 & Mild \\
$\leq 0$ & 0 & Mild \\
\hline
\end{tabular}

Heavy metal pollution in the garden contains not only heavy metal materials but also other elements and substances. Therefore, in order to comprehensively reflect the pollution of various heavy metal elements in the garden, numerous comprehensive pollution heatstroke is used to reflect the average pollution water level of heavy metal elements in the garden, as well as the pollution of each heavy metal element [16], given as follows:

$$
\begin{aligned}
U_{i} & =\frac{e_{i}}{s}, \\
U_{n} & =\frac{\sqrt{U_{i} U_{i}^{2}+U_{i} \max _{2}}}{2},
\end{aligned}
$$

where $U_{i}$ represents the pollution index of garden heavy metal elements relative to the evaluation reference values, while $e_{i}$ represents the actual value of an element of a garden heavy metal element, where $S$ shows the background values for the evaluation of $U_{i} U_{i}^{2}$ that represents the mean pollution index of heavy metal elements of the garden, while $U_{i} \max _{2}$ represents the pollution maximum index of the garden heavy metal elements.

The comprehensive potential ecological risk index of heavy metal elements should also be considered in the pollution of garden heavy metals, which is an important factor that affects the restoration ability of the plants [17]. Therefore, this study also calculates the potential ecological risk of garden heavy metal pollution, given as follows:

$$
\begin{aligned}
& R_{j}^{i}=T_{j}^{i} \times G_{j}^{i}, \\
& y_{j}^{i}=\frac{G_{j}^{i}}{G_{n}^{i}}, \\
& \mathrm{RI}=\sum_{i=1}^{n} R_{j}^{i} .
\end{aligned}
$$

In equation (3), $R_{j}^{i}$ represents the potential ecological hazard coefficient of garden heavy metal pollution, $T_{j}^{i}$ illustrates the toxic coefficient of heavy metal pollution in gardens, while $G_{j}^{i}$ demonstrates the single factor pollution index in garden heavy metal pollution. In equation (4), $y_{j}^{i}$ represents the measured heavy metal pollution, while in equation (5), RI shows the potential ecological hazard index of heavy metal pollution in gardens. 
After determining the correlation index of heavy metal pollution, the means of wavelet function is calculated. The wavelet network is a network model combining wavelet analysis technology and backpropagation neural network. The better wavelet analysis solves the serious lack of resolution in the time domain in Fourier transformation. Wavelet transform is the internal product of the wavelet function and the signal to be analyzed, and the local characteristics of the signal can be analyzed. In the prediction of this paper, the garden heavy metal pollution plants are first set to predict their repairability according to the setting of the plant [18]. The details of plant configuration in garden heavy metal pollution are shown in Table 2.

The plant restoration capabilities predicted in Table 2 are all highly effective plants and are very important in the restoration of garden heavy metal pollution. In the prediction of plant repair capability, the weight of plant repair capability is first determined as follows:

$$
T(a)=f_{i}\left(\frac{\sum_{i=1}^{k} w_{i j} x_{i}-b_{j}}{a_{i}}\right) .
$$

In equation (6), $T(a)$ represents the weight of plant restoration capabilities [19]. Since the weight of the acquired plant repair capability, the deviation needs to be corrected before the prediction, the help of the nuclear function, and the result is given as follows:

$$
U=H(x)=\operatorname{sgn}\left(\sum_{t=1}^{t} w_{t} K\left(S_{t}, x\right)+b\right) .
$$

In equation (7), $S_{t}$ represents the central point of the weight of plant restoration capabilities, while $w_{t}$ illustrates the correction factor [20, 21].

Then, with the help of the SH algorithm, the objective function is calculated and is given as follows:

$$
\min \sum(i, j) \in r s_{j}^{o} d_{i}^{h}
$$

Considering the above analysis, we constructed the plant restoration ability prediction model with the wavelet function to predict the plant restoration ability under the garden heavy metal pollution environment. Figure 1 shows the concept of the proposed prediction model.

The proposed plant restoration cable predictive model can be calculated mathematically as follows:

$$
f_{x}(a, b)=\frac{\sqrt{a}}{2 \pi} \int_{\vartheta}^{\beta} X(u) a(u) d(a) .
$$

In equation (9), $X(u)$ represents the Fourier transform function, $d(a)$ shows the phase moving along the left and right of the function, while $a$ demonstrates zoom-in and zoom-out capability $[22,23]$.

According to the constructed prediction model of plant repairability under garden heavy metal pollution environment, optimize the prediction value and improve the ability to predict plant repairability under garden heavy metal pollution environment given as follows:
TABLE 2: Plant configuration in heavy metal pollution in the garden.

\begin{tabular}{lcc}
\hline Plant name & Area & Study conditions \\
\hline Salix babylonica & Willow & Hydroponic experiment \\
Southeast & Stonecrop & Hydroponic experiment \\
Nandina & Berberidaceae & Field planting \\
Cedar & Panacea & Field planting \\
Mulberry & Mulberry & Field planting \\
Fragrans & Devilwood & Field planting \\
\hline
\end{tabular}

$$
B(k)=\sum_{i=1}^{j} w_{i j} f(x) \theta .
$$

In equation (10), $w_{i j}$ represents the connection weights of the output layer in the wavelet function implicit layer and $\theta$ demonstrates the node output value of the implied layer prediction result.

\section{Experimental Analysis}

This section of the paper represents the experimental results carried out via different experiments. The data was collected from the gardens; that is, samples of the soil were collected from the gardens. All the experiments were performed on a Laptop computer system having the specification of (Intel Core-i7, $7^{\text {th }}$ generation, having a processor of $2.71 \mathrm{GHz}$, $16 \mathrm{~GB}$ of RAM, and the operating system installed on the system was Ubuntu).

4.1. Experimental Scheme. This subsection demonstrates the experimental scheme of the proposed work. In order to verify the prediction ability of the proposed method, we selected the heavy metal pollution area having a length of 200 square meters and different plants and predicted its repairability with the help of the prediction algorithm used in this study. The data was obtained by collecting various samples of the soil. After the collection of data, it was passed through preprocessing stage in order to remove the noise and irrelevant data from the collected dataset. The experimental data is processed in more detail in order to get those features that are more important for the prediction results. The experimental environment is shown in Figure 2.

We performed multiple experiments in order to check the importance and significance of the proposed approach. Here, in this section, we have mentioned the top two experiments along with the parameter values and the results obtained via those experiments.

Table 3 shows the most relevant parameters and their information value in order to conduct experiment 1 .

To verify the effectiveness of the proposed method, a comparative study was also conducted with the two other previous approaches. The proposed system was better in terms of accuracy and predicted time overhead as compared to the previous methods. Figure 3 shows a comparison of the prediction accuracy of the proposed system with the other two methods, obtained through experiment 1 . 


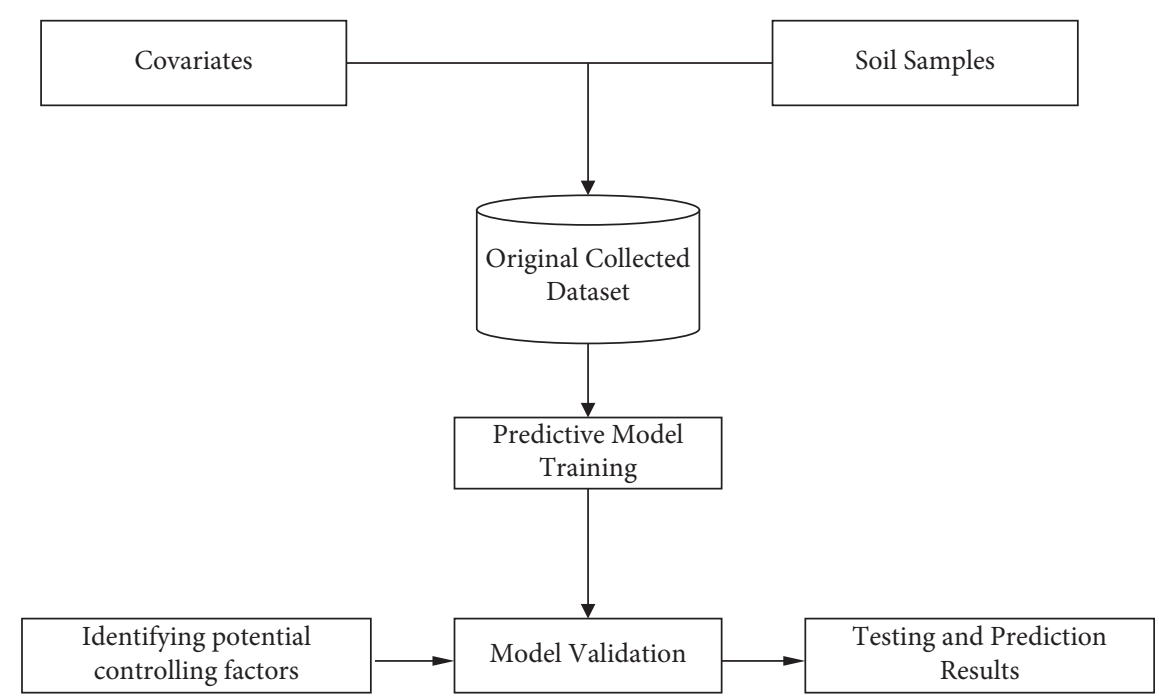

FIgURe 1: Proposed prediction model of plant restoration.

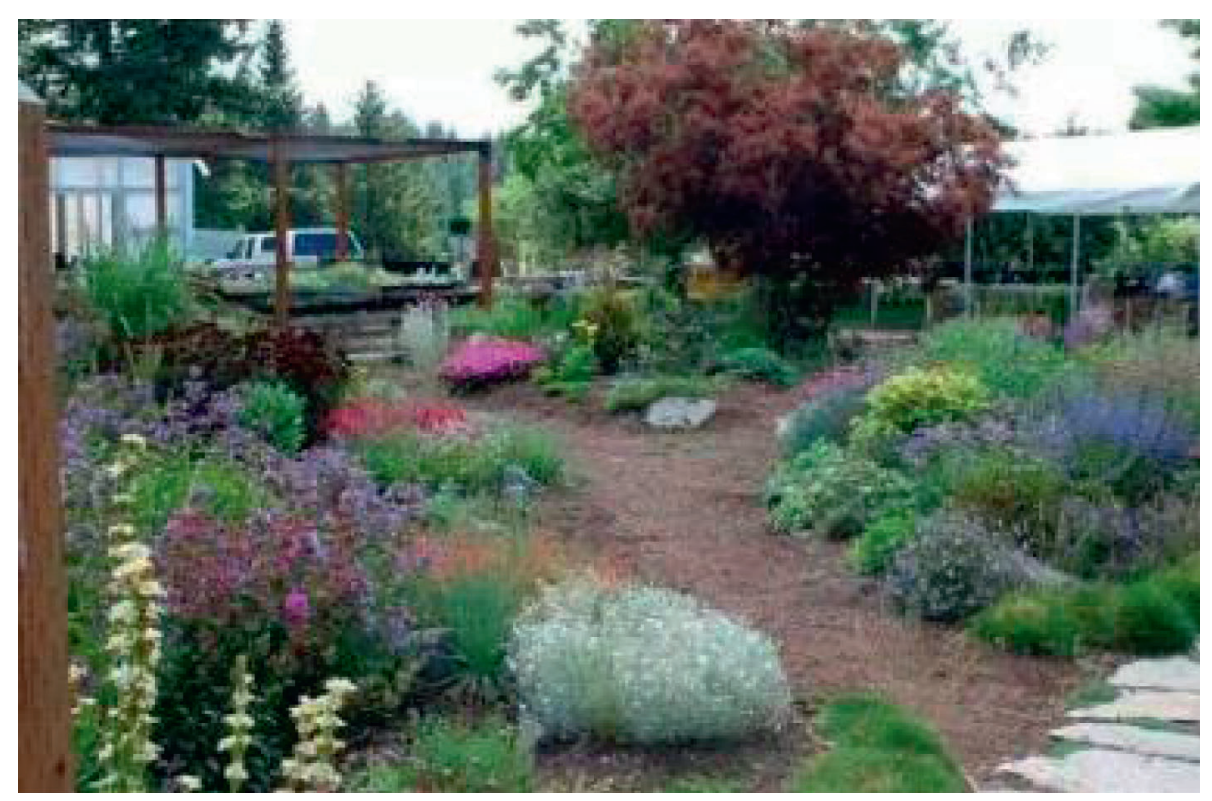

FIgURE 2: Local map of the experimental environment.

The analysis of data in Figure 3 shows that the prediction accuracy varies from method 1 to the proposed method. From Figure 3, it is obvious that the prediction accuracy of this method is always higher than $85 \%$ and always higher than the other two traditional prediction methods used in this study. The prediction accuracy of method 1 reached the maximum value of $84 \%$, while the maximum prediction accuracy value for method 2 observed was $90 \%$. Compared the prediction methods, the method used in this study and the methods used in the previous approaches, we found that the proposed system was much better than the other methods. Based on the proposed method, the garden pollution level was determined which reflects the average pollution level of the metals. On this basis, the plant repairability prediction model is constructed with the help of wavelet function, to predict the plant repairability under garden heavy metal pollution environment and to complete the prediction of plant repairability under garden heavy metal pollution environment.

In order to further verify the effectiveness of the proposed method, the time overhead of the two previous methods on the plant repairability of the heavy metal pollution area is shown in Figure 4.

Figure 4 shows the results of the three methods used in this study following the same experimental environment. Therefore, the prediction of the heavy metal polluted area is always less than $2 \mathrm{~s}$, and the heavy metal polluted area of the other two methods verified the effectiveness of this method.

The most relevant parameters and their information value for experiment 2 are shown in Table 4. 
TABle 3: Parameters' design of experiment 1.

\begin{tabular}{lc}
\hline Item name & Information value \\
\hline Plant planting duration (month) & 5 \\
Constitute & Two mountain peaks \\
Specific elevation of the highest peak & $132.4 \mathrm{~m}$ \\
Max elevation difference & $89.6 \mathrm{~m}$ \\
Slant area & $30 \%$ \\
Heavy metal pollution level & Second level \\
Number of landscape zones & 16 \\
Land-use-range shape & Irregular polygon \\
Rainfall conditions & Autumn and late summer are relatively dry heavy rainfall in late summer and early spring \\
Aspect change & More obvious \\
Climate conditions & Long summer, shorter winter, and humid and mild climate \\
Frost-free season & Around 270 days \\
Average annual air temperature & $16.8^{\circ} \mathrm{C}$ \\
Average annual precipitation & 1423 mm \\
Average annual rainfall day & 150 \\
Wind direction & Summer is mainly south wind; mainly north wind in winter and spring \\
Average annual sunshine hours & $1720 \mathrm{~h}$ \\
Relative humidity & $78 \%$ \\
Cumulative temperature & $5344^{\circ} \mathrm{C}$ \\
Soil sampling interval (day) & 10 \\
\hline
\end{tabular}

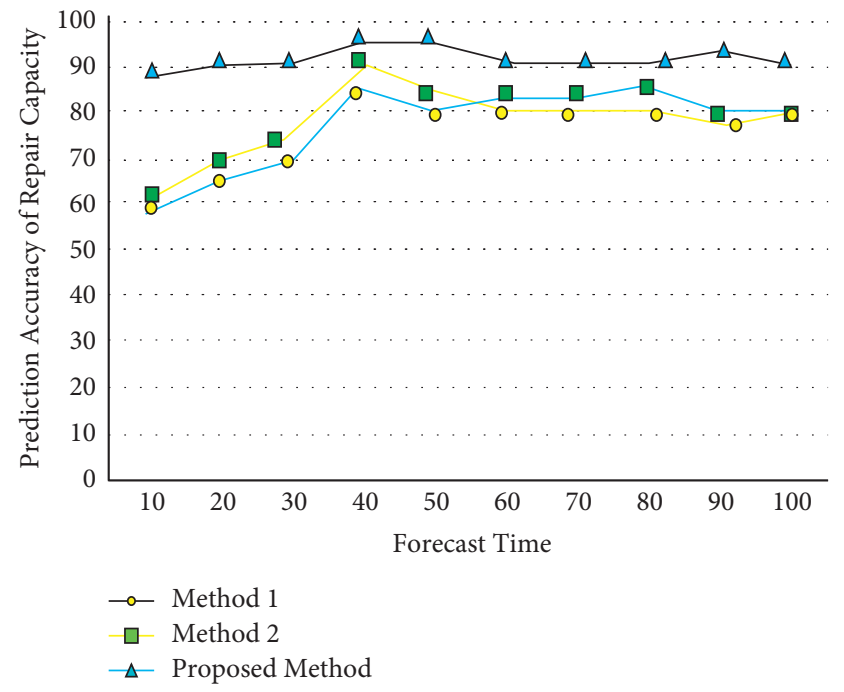

Figure 3: Comparison of prediction accuracy of different methods obtained through experiment 1 .

In order to show the significance and importance of the proposed method, a comparative study was conducted with the two previous approaches. From the experimental results, it was observed that the proposed method outclasses the two previous methods in terms of prediction accuracy and prediction time overhead. Figure 5 demonstrates the analysis of prediction accuracy of the proposed method and the other two previous methods.

Figure 5 shows the analysis of the proposed method and the other two previous approaches used in this study. From Figure 5, it is obvious that the prediction accuracy varies from method 1 to the proposed method. Figure 5 shows that the prediction accuracy of the proposed method is always higher than $86 \%$ and always higher than the other two traditional prediction methods used in this study. The

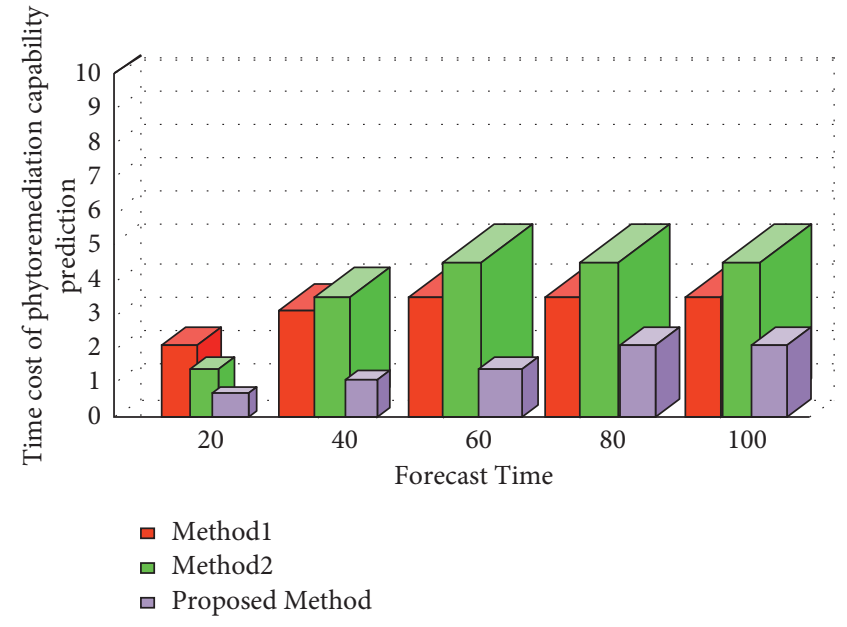

FIGURE 4: Forecast overhead of the utilized methods.

prediction accuracy of method 1 starts from $59 \%$ and reached a maximum value of $83 \%$, while the prediction accuracy of method 2 starts from $61 \%$ and reached a maximum prediction accuracy value of $85 \%$. By comparing the method used in this study and the methods used in the previous approaches, we found that the proposed system was much better than the other methods. Based on the proposed method, the prediction of garden pollution level was determined, and it was found that the prediction accuracy of the proposed method was way better than the other two state-of-the-art approaches. In addition, to show the significance and importance of the proposed method, an analysis of the prediction time overhead of the previous two methods and the proposed method was done. Figure 6 shows the prediction time overhead of the previous methods and the method proposed in this study.

Figure 6 represents the results of all the three methods used in this study, having the same experimental 
TABle 4: Parameters' design of experiment 2.

\begin{tabular}{lc}
\hline Item name & Information value \\
\hline Plant planting duration (month) & 6 \\
Constitute & Two mountain peaks \\
Specific elevation of the highest peak & $135.0 \mathrm{~m}$ \\
Max elevation difference & $95.0 \mathrm{~m}$ \\
Slant area & $30 \%$ \\
Heavy metal pollution level & Second level \\
Number of landscape zones & 18 \\
Land-use-range shape & Irregular polygon \\
Rainfall conditions & Autumn and late summer are relatively dry heavy rainfall in late summer and early spring \\
Aspect change & More obvious \\
Climate conditions & Long summer, shorter winter, and humid and mild climate \\
Frost-free season & Around 270 days \\
Average annual air temperature & $20.5^{\circ} \mathrm{C}$ \\
Average annual precipitation & 1435 mm \\
Average annual rainfall day & 155 \\
Wind direction & Summer is mainly south wind; mainly north wind in winter and spring \\
Average annual sunshine hours & $1720 \mathrm{~h}$ \\
Relative humidity & $80 \%$ \\
Cumulative temperature & $5340^{\circ} \mathrm{C}$ \\
Soil sampling interval (day) & 13 \\
\hline
\end{tabular}

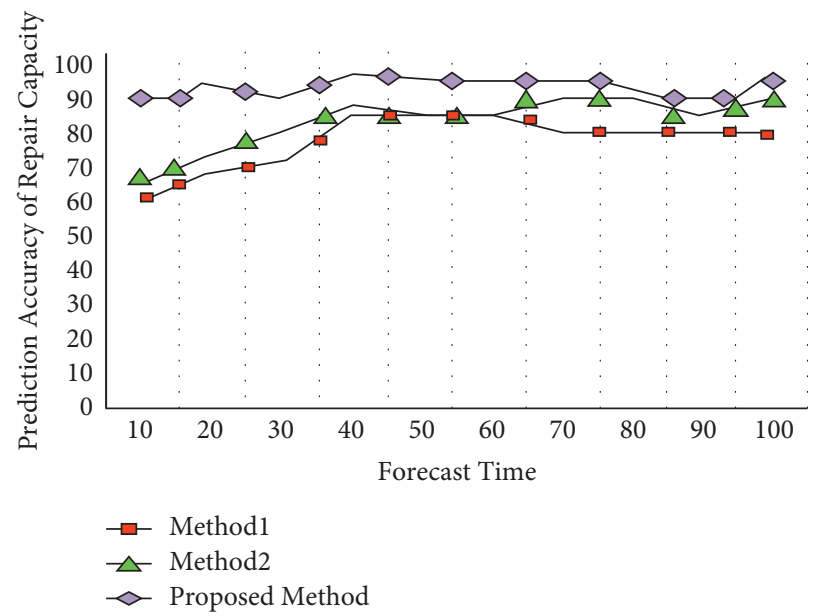

FIgURE 5: Comparison of prediction accuracy of different methods obtained through experiment 2.

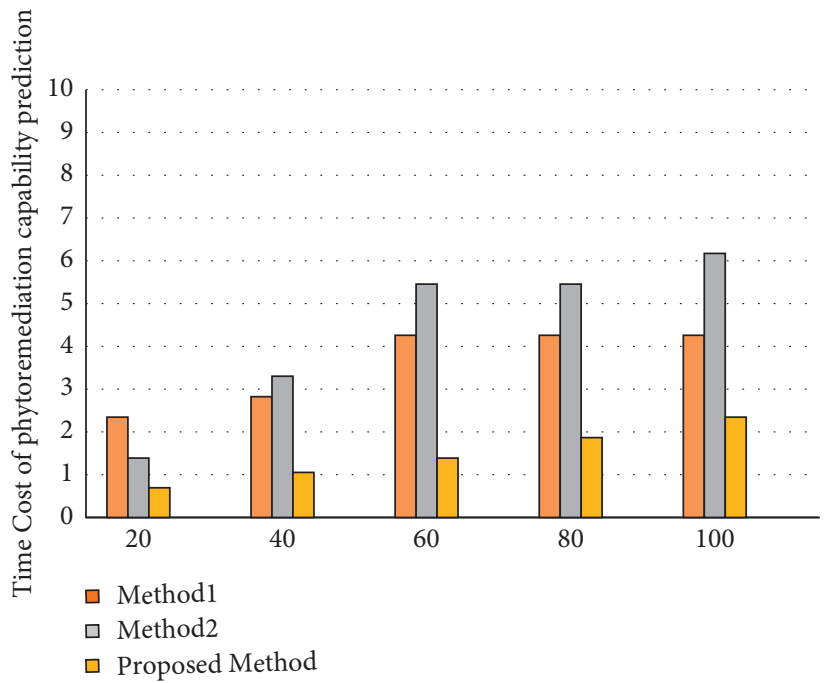

Figure 6: Different methods to forecast the time overhead of experiment 2. 
environment. From the experimental results shown in Figure 6, it is quite obvious that the performance of the proposed method is way better than the other two methods used in this study. Thus, the proposed method will be of great help to the agricultural environment and society, in order to predict the plan restoration ability in less time and with higher accuracy.

\section{Conclusion}

The gradual change and increase in environmental pollution have put everyone's life at a risk and is becoming a serious issue worldwide. Heavy metal pollution in the soil is dangerous for both the human and plants. The traditional methods used for the detection of heavy metals in the soil are atomic fluorescence spectroscopy, photometry, inductively coupled plasma optical emission spectroscopy, chemical analysis, and surface enhanced Raman spectroscopy. The major limitations associated with these approaches are time, material and resources, equipment, prediction accuracy, and they also require a lot of manpower. In order to overcome these issues, this study proposes a new prediction algorithm that predicts the heavy metal pollution in garden soil with a higher prediction accuracy and less time consumption. The proposed method analyzes the status of heavy metal pollution and pollution hazards and determines the composition of heavy metal pollution. In addition, it identifies the restoration technology of garden heavy metal pollution in plants and determines the level of garden heavy metal pollution with the help of the land accumulation index method. Further, it reflects the average pollution water level of garden heavy metal elements with the help of Numero comprehensive pollution heatstroke. On this basis, the prediction model of plant repairability is constructed with the help of wavelet function that predicts the plant repairability under garden heavy metal pollution environment. The experimental results show that the proposed algorithm predicts the heavy metal pollution environment with a higher accuracy and consumes less time for this process. Future work of this study is to design more prediction algorithms that process in much lesser time and to give higher accuracies. The collection of more data samples from different environments and different places and then presenting them to the prediction models is also one of the future studies.

\section{Data Availability}

The data used to support the findings of this study are available from the corresponding author upon request.

\section{Conflicts of Interest}

The authors declare that there are no conflicts of interest.

\section{References}

[1] Y. Gu, S. Li, W. Gao, and H. Wei, "Hyperspectral estimation of the cadmium content in leaves of Brassica rapa chinesis based on the spectral parameters," Acta Ecologica Sinica, vol. 35, pp. 4445-4453, 2015.
[2] O.-C. Modoi, C. Roba, Z. Török, and A. Ozunu, "Environmental risks due to heavy metal pollution of water resulted from mining wastes in NW Romania," Environ Eng Manage J, vol. 13, pp. 2325-2336, 2014.

[3] M. Berti, S. Bertini, C. Carrer, and F. Sorrentino, "Arsenic, cadmium, lead and mercury in biota from Venice lagoon: from sources to human exposure," Procedia Environ Sci Eng Manage, vol. 2, pp. 177-183, 2015.

[4] T. X. Lou, S. L. Lü, and Y. X. Li, "Application potential of Salicornia europaea in remediation of $\mathrm{Cd}, \mathrm{Pb}$ and $\mathrm{Li}$ contaminated saline soil," Chinese Journal of Biotechnology, vol. 36, no. 3, pp. 481-492, 2020.

[5] Y. Hu, J. Zhou, H. Liu, M. Gao, and J. Zhou, "Bibliometric analysis of studies on remediation of heavy metals contaminated soils based on Web of science," Acta Pedologica Sinica, vol. 55, no. 3, pp. 707-720, 2018.

[6] X. Zhang, J. Zhou, and M. Li, "Analysis on spatial and temporal changes of regional habitat quality based on the spatial pattern reconstruction of land use," Acta Geographica Sinica, vol. 75, no. 1, pp. 160-178, 2020.

[7] W. Ning, X. Lin, W. U. Peng, W. Suo, and H. U. Yuan, "Comparative analysis of the performance of various active queue management techniques to varying wireless network conditions," International Journal of Electrical and Computer Engineering, vol. 9, no. 1, pp. 359-368, 2019.

[8] L. Jin, Z. Zhang, N. Wang, Z. Liu, and Y. Fu, "Intensity distribution of partially coherent array finite airy beams propagating in atmospheric turbulence," International Journal of Optics, vol. 21, no. 7, pp. 46-57, 2021.

[9] L. I. Haichao, H. Ishidaira, K. Souma, and J. Magome, “Assessment $\mathrm{OF}$ the flood control capacity and cost efficiency OF sponge city construction IN mianyang city, China," Journal of Japan Society of Civil Engineers Ser G (Environmental Research), vol. 76, no. 5, pp. 46-57, 2020.

[10] F. R. Z. Hasibuan and I. Indayani, "The effect of application of SAK-ETAP, internal control system, and capacity of cooperatives on the development of business in cooperatives in banda aceh city," Journal of Accounting Research, Organization and Economics, vol. 2, no. 3, pp. 262-270, 2020.

[11] E. B. Aleksandrova, A. A. Shtyrkina, and A. V. Yarmak, "Isogeny-based cryptographic access control," Automatic Control and Computer Sciences, vol. 54, no. 8, pp. 803-812, 2020.

[12] M. Yoshida, T. Kan, and K. Kasai, "10 channel WDM 80 Gbit/ s/ch, 256 QAM Bi-directional coherent transmission for a high capacity next-generation mobile fronthaul," Journal of Lightwave Technology, vol. 18, no. 9, p. 1, 2020.

[13] Z. X. Yang, "Research on trade model of transaction costs based on ecommerce," Applied Mechanics and Materials, vol. 26-28, pp. 218-221, 2010.

[14] M. Yu, "Processing trade, tariff reductions and firm productivity: evidence from Chinese firms," The Economic Journal, vol. 125, no. 585, pp. 943-988, 2014.

[15] Y. Yu, X. Wang, R. Y. Zhong, and G. Q. Huang, "E-commerce logistics in supply chain management," Industrial Management \& Data Systems, vol. 117, no. 10, pp. 22632286, 2017.

[16] H. Zhu, C. X. J. Ou, W. J. A. M. van den Heuvel, and H. Liu, "Privacy calculus and its utility for personalization services in e-commerce: an analysis of consumer decision-making," Information \& Management, vol. 54, no. 4, pp. 427-437, 2017.

[17] D. A. Serel, "Production and pricing policies in dual sourcing supply chains," Transportation Research Part E: Logistics and Transportation Review, vol. 76, pp. 1-12, 2015. 
[18] R. Becerril-Arreola, M. Leng, and M. Parlar, “Online retailers' promotional pricing, free-shipping threshold, and inventory decisions: a simulation-based analysis," European Journal of Operational Research, vol. 230, no. 2, pp. 272-283, 2013.

[19] A. Aravind and M. Beena, "Electrochemical sensor based on nanostructured ion imprinted polymer for the determination of Cr (III) ions from industrial waste water," Polymer International, vol. 67, no. 12, pp. 1595-1604, 2018.

[20] C. Lin, N. Xiong, J. H. Park, and T.-H. Kim, "Dynamic power management in new architecture of wireless sensor networks," International Journal of Communication Systems, vol. 22, no. 6, pp. 671-693, 2009.

[21] Y. Sang, H. Shen, Y. Tan, and N. Xiong, "Efficient protocols for privacy preserving matching against distributed datasets," Information and Communications Security, vol. 23, no. 4, pp. 210-227, 2006.

[22] F. Long, N. Xiong, A. V. Vasilakos, L. T. Yang, and F. Sun, “A sustainable heuristic QoS routing algorithm for pervasive multi-layered satellite wireless networks," Wireless Networks, vol. 16, no. 6, pp. 1657-1673, 2010.

[23] J. Li, N. Xiong, J. H. Park, C. Liu, S. Ma, and S. Cho, "Intelligent model design of cluster supply chain with horizontal cooperation," Journal of Intelligent Manufacturing, vol. 23, no. 4, pp. 917-931, 2012. 